собенности липидного обмена у больных псориазом на фоне сопутствующего метаболического синдрома

А.Г. Пашинян ${ }^{1}$, Е.В. Донцова²

1 ГБОУ ВПО РНИМУ им. Н.И. Пирогова Минздрава России

117997, Москва, ул. Островитянова, д. 1

2 ГБОУ ВПО «Воронежская государственная медицинская академия им. Н.Н. Бурденко» Минздрава России 394000, г. Воронеж, ул. Студенческая, д. 10

Цель. Оценить особенности липидного обмена у больных псориазом с сопутствующим метаболическим синдромом (МС).

Материал и методы. В сыворотке крови больных псориазом определяли уровень общего холестерина (общий ХС), триглицеридов (ТГ), холестерина липопротеинов высокой плотности (ХС ЛПВП) фрерментативным методом на спектрофотометре с длиной волны 500 нм. Уровень холестерина липопротеинов низкой плотности (ХС ЛПНП) определяли расчетным методом по фрормуле W. Friedewald (1972). Холестериновый коэфрфициент атерогенности (ХКА) вычисляли по формуле ХКА = (ХС общий — ХС ЛПВП) / ХС ЛПВП.

Результаты. У больных вульгарным псориазом установлены нарушения липидного обмена, характеризующиеся развитием атерогенной дислипидемии с повышением в крови концентрации общего ХС, ТГ, ХС ЛПНП, снижением уровня ХС ЛПВП и увеличением ХКА. Более выраженные изменения имеют место у больных с сопутствующими метаболическими расстройствами.

Ключевые слова: псориаз, липидный обмен, холестериновый коэффициент атерогенности, метаболический синдром.

Контактная инсормация: ledn89@mail.ru. Вестник дерматологии и венерологии 2014; (4): 40—45. 


\title{
P articular features of lipid metabolism in psoriasis patients with concomitant metabolic syndrome
}

\author{
A.G. Pashinyan ${ }^{1}$, Ye.V. Dontsova² \\ ${ }^{1}$ The Russian National Research Medical University named after N.I. Pirogov (RNRMU) \\ Ostrovityanovastreet, 117997, Moscow, Russia \\ ${ }^{2}$ Voronezh State Medical Academy of a Name of N.N. Burdenko of Ministry of Health of Russia \\ Studencheskaya str. 10, Voronezh, 394000, Russia
}

Goal. To assess particular features of lipid metabolism in psoriasis patients with concomitant metabolic syndrome (MS). Materials and methods. Total cholesterol, triglycerides (TG) and high density lipoprotein cholesterol (HDL cholesterol) were determined in the blood serum of psoriasis patients by the enzymatic method using a spectrophotometer at the wavelength of $500 \mathrm{~nm}$. The level of low-density lipoprotein cholesterol (LDL cholesterol) was determined by the calculation method using W. Friedewald's formula (1972). The cholesterol atherogenicity ratio (CAR) was calculated by the formula: $\mathrm{CAR}=($ Total cholesterol $-\mathrm{HDL}$ cholesterol $) / \mathrm{HDL}$ cholesterol

Results. Patients suffering from psoriasis vulgaris are distinguished by lipid metabolism abnormalities characterized by the development of atherogenic dyslipidemia, increase in the total cholesterol, TG and LDL cholesterol in blood, reduction in the HDL cholesterol level and increased CAR. Patients with concomitant metabolic disorders have more obvious changes.

Key words: psoriasis, lipid metabolism, cholesterol atherogenicity ratio, metabolic syndrome. 
Популяционная частота псориаза в различных странах колеблется от 0,1 до 7\% в зависимости от климатогеографического региона: в странах Центральной Европы - от 2 до 4\%, в Австралии - более чем у $6 \%$ взрослого населения $[1,2]$. В Российской Федерации распространенность болезней кожи и подкожной клетчатки в 2012 г. достигла 6221,3, а заболеваемость - 4813,1 на 100 тысяч населения, больные псориазом составили 9,4\% [3]. В связи с хроническим и зачастую тяжелым течением псориаза проблема патогенеза является актуальной до настоящего времени $[1,4,5]$.

Многочисленные исследования связаны с изучением липидного обмена у больных псориазом [6-8]. В 2013 г. были опубликованы данные обследования 2,4 миллиона человек, проведенного в период с 1980 по 2012 г. в США. У 265512 был диагностирован псориаз, который у $80 \%$ пациентов был связан с дислипидемией [9]. До настоящего времени остаются вопросы, касающиеся особенностей нарушений липидного обмена при псориазе и особенно при сочетании дерматоза с другими коморбидными расстройствами [10-12].

Одним из коморбидных состояний является метаболический синдром (синдром Reaven, синдром peзистентности к инсулину), для которого характерны увеличение массы висцерального жира, снижение чувствительности периферических тканей к инсулину и гиперинсулинемия, нарушение углеводного, липидного, пуринового обмена, артериальная гипертензия [13].

Современные исследователи важную роль в развитии псориаза отводят изучению метаболических нарушений [11, 14-16]. В 2002 г. были опубликованы данные обследования взрослого населения США. В результате репрезентативной выборки у 47 миллионов жителей США выявлен метаболический синдром: окружность талии у мужчин превышала 102 см, у женщин - 88 см; уровень триглицеридов сыворотки крови составил не менее 1,69 ммоль/л; холестерин липопротеинов высокой плотности - менее 1,04 ммоль/л у мужчин и 1,29 ммоль/л у женщин; артериальное давление не менее 130/85 мм рт. ст.; уровень глюкозы в сыворотке > 6,1 ммоль/л [17].

В многочисленных научных работах отмечено, что увеличение массы тела приводит к повышению риска развития псориаза, а снижение веса оказывает положительное влияние на течение заболевания [8,18-20]. Атерогенная направленность метаболизма при псориазе приводит к развитию ишемической болезни сердца, тромбозам, цереброваскулярным нарушениям, гипертонии, инсулинорезистентности [18, 21-24].

Целью исследования явилось изучение особенностей липидного обмена у больных псориазом с сопутствующим метаболическим синдромом (MC).

\section{Материал и методы}

Группу исследования составили 296 больных вульгарным псориазом, из них 60 больных (29 женщин, 31 мужчина) без признаков МС (группа сравнения) и 236 больных (116 женщин, 120 мужчин) с признаками МС (основная группа). Контрольную группу составили 50 здоровых человек.

Наличие MC определяли на основе критериев Bceроссийского научного общества кардиологов и Российского медицинского общества по артериальной гипертензии (2009) [25].

У всех больных изучали антропометрические параметры (рост, вес, объем талии - ОТ, объем бедер ОБ, индекс массы тела - ИМТ), а также величину артериального давления (АД), биохимические тесты липидного спектра крови (общий холестерин - общий XC, триглицериды - ТГ, холестерин липопротеинов высокой плотности - ХС ЛПВП, холестерин липопротеинов низкой плотности - ХС ЛПНП). Для оценки распространенности и степени выраженности кожных проявлений псориаза определяли индекс PASI.

Уровень общего ХС оценивали энзиматическим методом - ферментативным колориметрическим тестом (CHOD PAP) с использованием реагентов Brocon Fluitest CHOL. XC ЛПВП измеряли спектрофотометрически ферментативным методом с использованием полимера и детергента фрирмы «Гален». Уровень ХС ЛПНП определяли расчетным методом по формуле W. Friedewald (1972): ХС ЛПНП (ммоль/л) = $=(\mathrm{XC} \mathrm{общий}-\mathrm{XC} \mathrm{ЛПВП)} \mathrm{-} \mathrm{ТГ/2,2.} \mathrm{ТГ} \mathrm{исследовали}$ энзиматическим ферментативным методом на спектрофотометре с длиной волны 500 нм.

Для оценки степени атерогенности крови использовали предложенный А.Н. Климовым в 1977 г. холестериновый коэффициент атерогенности (XKA), который вычисляли по формуле: XKA = (XC общий - ХС ЛПВП) / ХС ЛПВП.

Статистическая обработка данных проведена с помощью пакета статистических программ Statistica For Windows c вычислением средней арифметической и ее стандартной ошибки $(M \pm m)$. Различия между сравниваемыми группами считали достоверными при $p \leq 0,05$.

\section{Результаты}

У обследованных больных вульгарный псориаз имел среднюю степень тяжести со значением индекса PASI 49,53 \pm 0,46 балла в основной группе и 28,82 \pm 0,88 балла в группе сравнения. Возраст пациентов варьировал от 40 до 65 лет с длительностью заболевания от 1 года до 25 лет. У больных основной группы имелась сопутствующая артериальная гипертензия (АД $\geq 130 / 85$ мм рт. ст.), у пациентов группы сравнения АД было < 130/85 мм рт. ст.

Сравнительная характеристика отдельных антропометрических данных и исследуемых показателей 
Таблица Антропометрические данные и показатели липидного обмена (общий ХС, ТГ, ХС ЛПНП, ХС ЛПВП, XKA) у больных псориазом без MC, с МС и у здоровых лиц

\begin{tabular}{|c|c|c|c|}
\hline \multirow[b]{2}{*}{ Показатель } & \multirow{2}{*}{$\begin{array}{c}\text { Здоровые } \\
\text { лица } \\
(n=50)\end{array}$} & \multicolumn{2}{|c|}{ Больные псориазом ( $n=296)$} \\
\hline & & $\begin{array}{l}\text { без MC } \\
(n=60)\end{array}$ & $\begin{array}{c}\text { c MC } \\
(n=236)\end{array}$ \\
\hline ИМТ, кг/М² & $23,84 \pm 0,14$ & $27,46 \pm 0,13$ & $37,78 \pm 0,15^{* *}$ \\
\hline OT, см & $77,46 \pm 1,0$ & $90,55 \pm 0,55$ & $122,64 \pm 0,64^{* *}$ \\
\hline ХС общий, ммоль/л & $4,18 \pm 0,08$ & $5,25 \pm 0,06$ & $6,74 \pm 0,03^{* *}$ \\
\hline Триглицериды, ммоль/л & $1,25 \pm 0,03$ & $1,69 \pm 0,03$ & $2,69 \pm 0,02^{* *}$ \\
\hline ХС ЛПНП, ммоль/л & $2,11 \pm 0,06$ & $3,26 \pm 0,04$ & $4,68 \pm 0,02^{* *}$ \\
\hline ХС ЛПВП, ммоль/л & $1,5 \pm 0,03$ & $1,22 \pm 0,02$ & $0,83 \pm 0,01^{* *}$ \\
\hline XKA & $1,79 \pm 0,04$ & $3,36 \pm 0,05$ & $7,34 \pm 0,09 \cdot *$ \\
\hline
\end{tabular}

· $p<0,05-$ достоверность различий относительно здоровых лиц.

* $p<0,05-$ достоверность различий относительно больных псориазом без МС

липидного обмена (общий ХС, ТГ, ХС ЛПНП, ХС ЛПВП, XKA) у больных псориазом без MC, с МС и у здоровых лиц представлена в таблице.

Из таблицы видно, что больные основной группы имеют общее и абдоминальное ожирение. Так, у больных псориазом с метаболическим синдро-

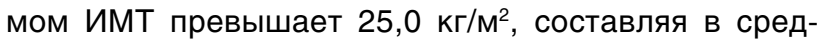
нем $37,78 \pm 0,15 \mathrm{kг} / \mathrm{M}^{2}$, ОТ - у женщин более $80 \mathrm{~cm}$, у мужчин - более 94 см со средним значением $122,64 \pm$ 0,64 см, что соответствует абдоминальному ожирению II степени. У больных группы сравнения ИМТ в среднем составляет 27,46 $\pm 0,13 \mathrm{kг} / \mathrm{M}^{2}$, ОТ у женщин $\leq 80 \mathrm{~cm}$, у мужчин $\leq 94 \mathrm{~cm}(90,55 \pm 0,55 \mathrm{~cm})$.

Представленные в таблице данные свидетельствуют об увеличении концентрации общего ХC в крови у больных псориазом: показатель общего $\mathrm{XC}$ у больных группы сравнения, без сопутствующего MC, равняется 5,25 \pm 0,06 ммоль/л, превышая в 1,3 раза значение этого показателя у здоровых лиц $-4,18 \pm 0,08$ ммоль/л $(p<0,05)$. При наличии признаков MC показатель общего XC у больных основной группы $(6,74 \pm 0,03$ ммоль/л) в 1,6 и 1,3 раза выше значений общего XС соответственно в группе здоровых лиц и в группе сравнения ( $p<0,05$ для обоих показателей).

У пациентов без признаков метаболических расстройств, по сравнению с контрольной здоровой группой, установлено увеличение концентрации ТГ в крови в 1,4 раза $(p<0,05)$, что составило $1,69 \pm 0,03$ ммоль/л. У пациентов, имеющих признаки сопутствующего МС, концентрация ТГ в крови достигает 2,69 0 0,02 ммоль/л, превышая в 2,2 раза уровень ТГ у здоровых лиц и в 1,6 раза - у больных без МС ( $p<0,05$ для обоих показателей).
У больных псориазом из группы сравнения отмечается повышение концентрации ХС ЛПНП в крови до 3,26 \pm 0,04 ммоль/л, или в 1,5 раза относительно группы здоровых лиц -2,11 $\pm 0,06$ ммоль/л $(p<0,05)$. У больных псориазом основной группы определяется более значимое увеличение концентрации ХС ЛПНП до 4,68 \pm 0,02 ммоль/л, что в 2,2 раза больше уровня ХC ЛПНП в группе здоровых лиц и в 1,4 раза выше уровня исследуемого показателя у пациентов с псориазом без MC ( $p<0,05$ для обоих показателей).

На фоне высоких концентраций общего ХС, ТГ, ХС ЛПНП у больных обеих групп имеет место уменьшение содержания в сыворотке крови ХС ЛПВП. Так, у больных группы сравнения уровень ХС ЛПВП равняется 1,22 \pm 0,02 ммоль/л, что в 1,2 раза ниже аналогичного показателя у здоровых лиц - 1,5 \pm 0,03 ммоль/л $(p<0,05)$. При наличии у пациентов признаков МС количество ХС ЛПВП в крови уменьшается до $0,83 \pm 0,01 \mathrm{ммоль/л,} \mathrm{что} \mathrm{соответственно} \mathrm{в} 1,8$ и 1,5 раза ниже уровня ХС ЛПВП в группе здоровых лиц и в группе сравнения ( $p<0,05$ для обоих показателей).

Данные, представленные в таблице, указывают также на значимое увеличение холестеринового коэффициента атерогенности у больных псориазом, который у больных группы сравнения превышает норму в 2,2 раза, а у больных основной группы - в 4,1 раза ( $p<0,05$ для обоих показателей). Сравнительный анализ XKA у больных псориазом без MC $(3,36 \pm 0,05)$ и у больных псориазом с МС $(7,34 \pm 0,09)$ свидетельствует о статистически значимых различиях изучаемого параметра в исследуемых группах больных: более высокий ХКА выявлен в группе пациентов с признаками MC: он превышает в 2,2 раза XKA у больных без MC $(p<0,05)$. 


\section{Заключение}

Проведенное исследование продемонстрировало наличие атерогенных изменений в крови у пациентов, страдающих псориазом.

Полученные нами данные показывают, что липидные нарушения, выявленные у больных псориазом, представлены всеми компонентами наиболее частого варианта атерогенной дислипидемии - «липидной триады»: гипертриглицеридемией, низким уровнем ХС ЛПВП и повышенной фрракцией липопротеинов низкой плотности - ХС ЛПНП, имеющих большое значение в оценке атерогенеза [9, 17, 26-28]. Липопротеины низкой плотности являются основным атерогенным классом. Как известно, повышение концентрации ЛПНП в крови, вызванное избыточным синтезом или сниженным катаболизмом, причинно связано с атеросклерозом. Липопротеины высокой плотности современной науке известны как класс антиатерогенных липопротеинов, выполняющих важную функ- цию - эвакуацию избытков холестерина из сосудистой стенки и тканей.

Установленные признаки дислипидемии у обследованных нами больных псориазом в большей степени выражены при наличии сопутствующих метаболических расстройств, что подтверждается повышением холестеринового коэффициента атерогенности, связанного с риском развития атеросклероза. У больных псориазом без МС (XKА в пределах 3,0-4,0) ассоциируется с умеренным, а у больных с псориазом и МС (XKA больше $4,0)$ - с высоким риском развития атеросклероза.

Наши исследования подтверждают мнение ученых, придающих существенное значение влиянию дислипидемии на основные механизмы развития псориаза $[6,7,9]$.

Оценка липидного статуса на системном уровне при псориазе является существенным дополнением к пониманию не только патогенеза заболевания, но и выбора рациональной терапии. I

\section{Литература}

1. Langley R., Krueger G., Griffiths C. Psoriasis: epidemiology, clinical features and quality of life. Ann. Rheum. Dis. 2005; 64 (Suppl II): 18-23.

2. Cowen P. Management of psoriasis. Aust. Fam. Physician. 2001; 30 (11): 1033-1037.

3. Kubanova A.A., Kubanov A.A., Melekhina L.E. et al. Results of the analysis of dermatovenerologic healthcare organizations activity in the Russian Federation for 2012. Vestn dermatol venerol 2013; 5: 21—39. [Кубанова А.А., Кубанов А.А., Мелехина Л.Е. и др. Результаты анализа деятельности медицинских организаций дерматовенерологического профиля в Российской Федерации за 2012 год. Вестн дерматол венерол 2013; (5): 21—39.]

4. Pashinyan A.G., Heydar S.A., Arutyunyan G.B., Dzhavayeva D.G. Psoriasis: etiology, pathogenesis, clinical manifestations. Vestn. esthetic medicine. 2014; 13 (1): 79—85. [Пашинян А.Г., Хейдар С.А., Арутюнян Г.Б., Джаваева Д.Г. Псориаз: этиология, патогенез, клинические проявления. Вестн эстетич мед 2014; 13 (1): 79_-85.]

5. Christophers E. Psoriasis - epidemiology and clinical spectrum. Clin. Exp. Dermatol. 2001; 26 (4): 314-320.

6. Yakubovich A. I. Correction of violations of a lipidic exchange at patients with psoriasis. Russian Journal of Skin and Sexually Transmitted Diseases. 2011; 6: 29—32. [Якубович А.И. Коррекция нарушений липидного обмена у больных псориазом. Росс журн кож и вен бол 2011; (6): 29-32.]
7. Butov Yu.S.,Vasenova V.Yu.,Shmakova A.S etc. Clinical and biochemistry status at patients with psoriasis and methods of its correction. Russian Journal of Skin and Sexually Transmitted Diseases. 2009; 5: 23-27. [Бутов Ю.С., Васенова В.Ю., Шмакова А.С. и др. Клиникобиохимический статус у больных псориазом и методы его коррекции. Росс журн кожн и вен бол 2009; (5): 23—27.]

8. Akcali C., Buyukcelik B., Kirtak N. et al. Clinical and laboratory parameters associated with metabolic syndrome in Turkish patients with psoriasis. J. Int. Med. Res. 2014; 42(2): 386-394.

9. Ma C., Harskamp C.T., Armstrong E.J., Armstrong A.W. The association between psoriasis and dyslipidaemia: a systematic review. Br. J. Dermatol. 2013; 168 (3): 486—495.

10. Mamedov M.N. Manual on diagnostics and treatment of a metabolic syndrome. M.: Multiprint. 2005. [Мамедов М.Н. Руководство по диагностике и лечению метаболического синдрома. М.: Мультипринт. 2005.]

11. Al-Mutairi N., Al-Farag S., Al-Mutairi A. et al. Comorbidities associated with psoriasis: an experience from the Middle East. J. Dermatol. 2010; 37: 146-155.

12. Christophers E. Comorbidities in psoriasis. Clin. Dermatol. 2007; 25 (6): 529—534.

13. Chazova I.E., Mychka V.B. Metabolic syndrome. M, 2004. 60-70. [Чазова И.Е., Мычка В.Б. Метаболический синдром. М., 2004. 60-70.]

14. Kim C.R., Lee J.H. An observational study on the obesity and metabolic status of psoriasis patients. Ann. Dermatol. 2013; 25 (4): 440—444.
15. Azfar R., Gelfand J. Psoriasis and metabolic disease: epidemiology and pathophysiology.Curr. Opin. Rheumatol. 2008; 20 (4): 416 — 422.

16. Gisondi P., Girolomoni G. Psoriasis and atherothrombotic diseases: disease-specific and nondisease-specific risk factors. Semin. Thromb. Hemost. 2009; 35: 313—324.

17. Ford E.S., Giles W.H., Dietz W.H. Prevalence of the metabolic syndrome among US adults: findings from the third National Health and Nutrition Examination Survey. JAMA. 2002; 287 (3): $356-359$.

18. Jensen P., Thyssen J.P., Zachariae C. et al. Cardiovascular risk factors in subjects with psoriasis: a cross-sectional general population study. Int. J. Dermatol. 2013; 52 (6): 681—683.

19. Solomon $\mathrm{G}$. The role of weight loss in the treatment of psoriasis: evidence that psoriasis is a systemic inflammatory disorder linked to metabolic syndrome. Br. J. Dermatol. 2014; 170 (3): 492-493.

20. Farshchian M., Ansar A., Sobhan M.R. Psoriasis and risk factors of metabolic syndrome: A case-control study. Dermatology \& Cosmetic. 2013; 4 (1): 10-18

21. Papp K., Poulin Y., Vieira A. Examining the risk of cardiovascular disease in patients with psoriasis: a critical review. J. Cutan. Med. Surg. 2013; 17 (2): 89-105.

22. Grozdev I., Kast D., Cao L.et al. Physical and mental impact of psoriasis severity as measured by the compact Short Form-12 Health Survey (SF-12) quality of life tool. J. Invest. Dermatol. 2012; 132: 1111—1116. 
23. Eckel R.H., Grundy S.M., Zimmet P.Z. The metabolic syndrome. Lancet. 2005; 365: 1415-1428.

24. Gelfand J.M., Dommasch E.D., Shin D.B. et al. The risk of stroke in patients with psoriasis. J. Invest. Dermatol. 2009; 129: 2411—2418.

25. Recommendations of experts of the All-Russian scientific organization of cardiologists about diagnostics and treatment of a metabolic syndrome: second revision. M., 2009. 28 p. [Рекомендации экспертов Всероссийского научного общества кардиологов по диагностике и лечению метаболического синдрома: второй пересмотр. М., 2009. 28 с.]
26. Komisarenko I.A. Metabolic syndrome as a polimorbidity problem. Consiliummedicum. Cardiology. 2012; 14 (1): 13-17. [Комисаренко И.А. Метаболический синдром как проблема полиморбидности. Consilium medicum. Кардиология. 2012; 14 (1): 13-17.]

27. Sigurdardottir G., Ekman A.K., Stahle M. et al. Systemic treatment and narrowband ultraviolet B differentially affect cardiovascular risk markers inpsoriasis J Am Acad Dermatol 2014; 19.
28. Mikryukov A.V. Features of a course of psoriasis at patients with the excess body weight and obesity. Clinical dermatol. andvener. 2013; 6: 52-56. [Микрюков А.В. Особенности течения псориаза у больных с избыточной массой тела и ожирением. Клин дерматол и венерол 2013; (6): 52—56.]

об авторах:

А.Г. Пашинян - д.М.Н., профессор кафедры дерматовенерологии лечебного факультета ГБОУ ВПО РНИМУ им. Н.И. Пирогова Минздрава России, Москва

Е.В. Донцова — к.м.Н., ассистент каффедры дерматовенерологии ГБОУ ВПО ВГМА им. Н.Н. Бурденко Минздрава России, Воронеж

\section{Конфликт интересов}

Авторы заявляют об отсутствии потенциального консрликта интересов, требующего раскрытия в данной статье 